\title{
UV Reflectance of the Ocean from DSCOVR/EPIC: Comparisons with a Theoretical Model and Aura/OMI Observations
}

\author{
AleXANDER VASILKov \\ Science Systems and Applications, Inc., Lanham, Maryland \\ ALEXEI LyAPUSTIN \\ NASA Goddard Space Flight Center, Greenbelt, Maryland \\ B. GREG MitCHELL \\ Scripps Institute of Oceanography, La Jolla, California \\ DONG HUANG \\ Science Systems and Applications, Inc., Lanham, Maryland
}

(Manuscript received 30 August 2018, in final form 11 July 2019)

\begin{abstract}
Ultraviolet (UV) data collected over the ocean by the Earth Polychromatic Imaging Camera (EPIC) on the Deep Space Climate Observatory (DSCOVR) are used. The Multi-Angle Implementation of Atmospheric Correction (MAIAC) algorithm adapted for EPIC processing performs cloud detection, aerosol retrievals, and atmospheric correction providing the water-leaving reflectance of the ocean at 340 and $388 \mathrm{~nm}$. The water-leaving reflectance is an indicator of the presence of absorbing and scattering constituents in seawater. The retrieved water-leaving reflectance is compared with full radiative transfer calculations based on a model of inherent optical properties (IOP) of ocean water in UV. The model is verified with data collected on the Aerosol Characterization Experiments (ACE) Asia cruise supported by the NASA Sensor Intercomparison for Marine Biological and Interdisciplinary Ocean Studies (SIMBIOS) project. The model assumes that the ocean water IOPs are parameterized through a chlorophyll concentration. The radiative transfer simulations were carried out using the climatological chlorophyll concentration from the Moderate Resolution Imaging Spectroradiometer (MODIS) on board the Aqua satellite. The EPIC-derived water-leaving reflectance is also compared with climatological Lambertian-equivalent reflectivity (LER) of the ocean derived from measurements of the Ozone Monitoring Instrument (OMI) on board the NASA polar-orbiting Aura satellite. The EPIC reflectance agrees well (within 0.01) with the model reflectance except for oligotrophic oceanic areas. For those areas, the model reflectance is biased low by about 0.01 at $340 \mathrm{~nm}$ and up to 0.03 at $388 \mathrm{~nm}$. The OMI-derived climatological LER is significantly higher than the EPIC water-leaving reflectance, largely due to the surface glint contribution. The globally averaged difference is about 0.04 .
\end{abstract}

\section{Introduction}

A main challenge of satellite remote sensing of the ocean is that only a small fraction of the top-of-atmosphere (TOA) radiance originates from water-leaving radiance while most of the signal comes from the atmosphere and to less extent from reflection at the air-water interface. These contributions from the atmosphere and

Corresponding author: Alexander Vasilkov, alexander.vasilkov@ ssaihq.com the air-water interface should be removed to retrieve useful information about ocean biogeochemical parameters. The existing atmospheric correction methods are based on instrument bands in the red-near-infrared and proved to achieve a reasonable retrieval accuracy of water-leaving radiance in the visible (Gordon and Wang 1994; Gordon 1997). However, these atmospheric correction methods may not achieve the required accuracy of water-leaving radiance in ultraviolet (UV). Additionally, water-leaving radiance retrievals in the UV will be challenging in the presence of absorbing aerosols, whose 
absorption significantly increases in the UV (Torres et al. 2007). Recognizing the exploratory nature of the oceanic UV retrievals, we apply the Multi-Angle Implementation of Atmospheric Correction (MAIAC) algorithm originally developed for the Moderate Resolution Imaging Spectroradiometer (MODIS) (Lyapustin et al. 2012, 2018) to processing of the Earth Polychromatic Imaging Camera (EPIC) on board of the Deep Space Climate Observatory (DSCOVR) data in UV.

A few models of the UV radiation field in ocean waters have been developed for past two decades. An essential component of the in-water radiation field model is a model of ocean water inherent optical properties (IOPs) in the UV spectral region. A simplified version of the IOP model in UV was already used in our calculations of underwater UV radiation fields on a global scale (Vasilkov and Krotkov 1997; Vasilkov et al. 2001). The IOP model in UV was updated in Vasilkov et al. (2005) and used to generate a lookup table of upward and downward irradiances with the Hydrolight radiative transfer (RT) model (Mobley 1994). A robust and properly validated algorithm for the retrieval of UV diffuse attenuation coefficients from remote sensing reflectances was proposed by Fichot et al. (2008). Penetration of UV irradiance into the global ocean was studied in Smyth (2011) using empirical in-water diffuse attenuation coefficient relationships derived from in situ measured profiles of IOPs at visible wavelengths and downwelling UV irradiances. Lee et al. (2013) proposed a semianalytical model of the diffuse attenuation coefficient of UV-visible solar radiation in the global ocean based on input from ocean color remote sensing. The model applied to MODIS measurements showed that the UV-A radiation penetration depth defined as a depth of $10 \%$ of the surface radiation was $50-70 \mathrm{~m}$ in oligotrophic waters.

Increased levels of biologically harmful UV radiation (290-400 nm) resulting from the depletion of Earth's ozone layer have been shown to affect aquatic ecosystems. One of the important effects of enhanced levels of UV radiation is a reduction in the productivity of phytoplankton caused by inhibition of photosynthesis due to damage to the photosynthetic apparatus (Vincent and Neale 2000). This effect has been confirmed by field observations. Numerous studies report the loss of phytoplankton productivity beneath the Antarctic ozone hole as compared with outside the ozone hole as ranging from $1 \%$ (Arrigo 1994) to $5 \%-10 \%$ (Smith and Cullen 1995; Neale et al. 1998). Knowledge of UV radiation penetration is important for evaluation of ecosystem properties including ecosystem health and primary productivity (Hader et al. 2007). Enhanced UV radiation can also affect the photochemical decomposition of dissolved organic matter (Moran and Zepp 1997) and the photochemical production of carbonyl sulfide in seawater (Zepp and Andreae 1994), thereby augmenting the greenhouse effect and affecting other long-term global biogeochemical cycles. Lee et al. (2013) showed that penetration of UV solar radiation can be estimated from ocean remote sensing. The changes in clouds and aerosols modulate biologically harmful UV radiation reaching Earth's surface and penetrating to ecologically significant depths in natural waters. Such changes can be estimated on a global scale by combining estimates of surface spectral irradiance derived from EPIC atmospherically corrected data with an existing model of UV radiative transfer in the ocean (Vasilkov et al. 2005; Smyth 2011; Lee et al. 2013).

In this paper, we focus on the UV pursuing two main goals: 1) to show that atmospheric correction over the ocean can be successfully performed in UV, and 2) to check consistency between the observed atmospherically corrected ocean reflectance and the modeled ocean reflectance on a global scale. The paper is structured as follows. In section 2 we describe satellite and in situ data and theoretical methods used in the study. Section 3 reports results and section 4 provides a discussion of the results. Conclusions are given in section 5 .

\section{Data and methods}

This section provides information on satellite data collected by DISCOVR/EPIC and Aura/Ozone Monitoring Instrument (OMI), atmospheric correction applied to the data, and a model of ocean reflectance.

\section{a. EPIC data}

The NOAA DSCOVR is parked at the first Lagrange point, L1, approximately 1.5 million $\mathrm{km}$ from Earth toward the sun. The Earth Polychromatic Imaging Camera (EPIC) on board DSCOVR views the entire sunlit disk of Earth with 10 narrowband filters at a spatial resolution about $8 \mathrm{~km}$ at nadir (Marshak et al. 2018). To reduce data rate all bands except the blue one are $2 \times 2$ aggregated on board. EPIC has two UV bands at 340 and $388 \mathrm{~nm}$, which are used in this study. The waterleaving radiance composes a small fraction of the TOA radiance, typically about $10 \%$. That is why the accurate radiometric calibration of a satellite instrument is important. For UV channels, in-flight EPIC radiometric calibration is accomplished by comparison to the reflectance values measured by the well-calibrated Suomi NPP Ozone Mapping and Profiler Suite (OMPS). Details of the UV channel calibration are given in 
Herman et al. (2018). At visible wavelengths, EPIC TOA reflectance was cross calibrated to MODIS using time-matched observations of the cloud-free and largescale highly homogeneous cloudy scenes at identical view geometries (Geogdzhayev and Marshak 2018).

\section{b. Atmospheric correction}

The DSCOVR EPIC data processing was done with the NASA MAIAC algorithm originally developed for MODIS (Lyapustin et al. 2012, 2018), and adapted for the EPIC sensor. While the detailed description of MAIAC over water processing will be given separately, here we provide a condensed description of our approach. The overwater processing is based on the standard radiative transfer model:

$$
L^{M}=L_{0}+\rho_{w} E T .
$$

Here, $L^{M}$ is a measured radiance, and $L_{0}$ is the TOA radiance that includes aerosol, Rayleigh, and wind speed-dependent glint and whitecaps contributions. It is computed using vector radiative transfer code Atmospheric Polarization Computations (APC) (Korkin et al. 2013). The second term on the right-hand side is a contribution from the water-leaving radiance, where $E$ is irradiance at the surface and $T$ is upward atmospheric transmittance. Functions $E$ and $T$ are calculated with the RT code Spherical Harmonics (SHARM) (Lyapustin 2005), and along with $L_{0}$ are stored in the lookup tables (LUTs) precomputed for a set of aerosol models. Here, $L_{0}$ in MAIAC LUTs is computed for three wind speeds $\left(v=2,6\right.$, and $\left.10 \mathrm{~m} \mathrm{~s}^{-1}\right)$ with interpolation to a specific National Centers for Environment Prediction (NCEP) value of wind speed. In Eq. (1), $L^{M}, L_{0}$, and $E$ are normalized to the extraterrestrial solar irradiance. According to a conventional definition used in the MODIS ocean products (Mobley et al. 2016), $\rho_{w}$ used in Eq. (1) is the remote sensing reflectance, which is related to the water-leaving reflectance via a factor of $\pi$. Below in this paper, we call $\rho_{w}$ the water-leaving reflectance, though it should be divided by $\pi$ for a direct correspondence to the MODIS product.

The ocean processing uses linear mixing of the fine and coarse marine aerosol models (Wang and Gordon 1994). The theoretical TOA radiance is a function of aerosol optical depth (AOD) $\tau$, fine-mode fraction (FMF) $f$, and water-leaving reflectance $\rho_{w}$ :

$$
L^{t} \cong f L^{F}\left(\tau, \rho_{w}\right)+(1-f) L^{C}\left(\tau, \rho_{w}\right),
$$

where the fine- and coarse-mode radiances (superscripts $F$ and $C$ ) are computed from the respective LUTs using Eq. (1). The aerosol models were adapted from Sayer et al. (2012, 2018a) and regionally modified with respect to absorption (viz., imaginary refractive index) to improve agreement of MAIAC AOD with global maritime or coastal Aerosol Robotic Network (AERONET) (Holben et al. 2001) AOD measurements. MAIAC overwater processing starts with cloud detection, followed by aerosol retrieval and atmospheric correction. The aerosol algorithm derives the aerosol optical depth and fine mode fraction from 550,680 , and $780 \mathrm{~nm}$. While the full detail of the algorithm will be described separately, here we provide the general idea. Our processing starts with gridding of the TOA L1B data to $10-\mathrm{km}$ resolution using global sinusoidal projection. For each $10-\mathrm{km}$ grid cell and each individual EPIC observation, the aerosol retrieval finds AOD and FMF minimizing the root-mean-square (RMS) error between the measurements at 550, 680, and $780 \mathrm{~nm}$ and theoretical TOA radiance given by Eqs. (1) and (2). The theoretical radiance depends on the waterleaving reflectance. Initially, we assume that the water is black in the red and near-infrared, and use $\rho_{w}=0.005$ at $550 \mathrm{~nm}$ similar to the standard dark target algorithm assumptions over the water (Levy et al. 2013).

The values of $\rho_{w}$ at 550 and $680 \mathrm{~nm}$ are dynamically updated using the multiangle daily retrievals. Technically, MAIAC implements a sliding window algorithm and stores up to 40 previous observations in memory creating the queue used for retrievals of the bidirectional reflectance distribution function (BRDF) over land from the accumulated cloud-free multiangle set of observations. We use the same technique over the ocean to accumulate the multiangle dataset for each grid cell from the cloud-free data on a daily basis. Additionally, observations are limited to clean atmospheric conditions (AOD $<0.25$ ) when we can assume that the aerosol properties are stable during the day. This is a realistic assumption for the open ocean, although it may not hold in the coastal regions. We also limit the range of sun-view zenith angles to about $50^{\circ}$ to avoid significant BRDF effects (Morel and Gentili 1996). When the number of angles (index $k$ ) exceeds three at sufficient variation of the view geometry, the full set of parameters $\left(\tau, f, \rho_{w}^{550}, \rho_{w}^{680}\right)$ is retrieved by minimizing the residual at the same three wavelengths:

$$
\sum_{k} \sum_{\lambda}\left(L_{k, \lambda}^{M}-L_{k, \lambda}^{T}\right)^{2}=\min
$$

The retrieved values of the water-leaving reflectance are stored in the queue memory for each $10-\mathrm{km}$ grid cell, and are dynamically updated with the latest retrievals, which are additionally filtered based on the 
final value of the RMS error [Eq. (3)]. Once the $\rho_{w}^{550}$, $\rho_{w}^{680}$ are initialized, they are used in the AOD-FMF EPIC retrievals from the single-angle observations.

A recently performed intercomparison between multiple global aerosol products over the ocean shows that MAIAC EPIC AOD nearly matches the Satellite Ocean Aerosol Retrieval (SOAR) algorithm for Visible Infrared Imaging Radiometer Suite (VIIRS) global performance, and is closest to the SOAR among all investigated products (Sayer et al. 2018b). It was also found that EPIC FMF is on the upper boundary of the "family" of aerosol products. The globally average EPIC Ångström exponent (AE 0.7) derived from 550 and $780 \mathrm{~nm}$ is somewhat higher than the "family average" $\mathrm{AE} \sim 0.5$, which needs to be understood. Following aerosol retrievals, MAIAC performs atmospheric correction deriving $\rho_{w}$ from Eq. (1) in the visible spectral bands as well as at 340 and $388 \mathrm{~nm}$.

\section{c. OMI data}

The OMI flying on the NASA polar-orbiting Aura satellite is a hyperspectral radiometer that measures radiance in UV and visible. Radiometric calibration and overall in-flight performance of OMI are described in Schenkeveld et al. (2017). To characterize the ocean reflectance, we use the so-called Lambertian-equivalent reflectivity (LER) derived from OMI-measured TOA radiance $I_{\mathrm{TOA}}$ using the following equation:

$$
I_{\mathrm{TOA}}=I_{0}+\mathrm{LER} \times F \times T /(1-\mathrm{LER} \times S),
$$

where $I_{0}, F, T$, and $S$ are computed for the Rayleigh atmosphere: $I_{0}$ is the TOA (path) radiance computed over a black surface, $F$ is the total (direct plus diffuse) solar irradiance reaching the surface and divided by $\pi, T$ is the upward atmospheric transmittance, and $S$ is the spherical albedo of the atmosphere. Functions $I_{0}$, $F, T$, and $S$ depend on wavelength and surface pressure; $I_{0}, F$, and $T$ also depend on sun-view geometry. Calculation of LER from Eq. (1) removes Rayleigh scattering only. To minimize aerosol and cloud contributions to the TOA radiance, the LER is selected as a minimum value from a long time series of observations (Herman and Celarier 1997). The final product is a monthly climatology of minimum LERs derived from the multiyear OMI record (Kleipool et al. 2008).

\section{d. Ocean reflectance model}

To calculate ocean reflectance, we use a lookup table of upward and downward irradiances computed with the Hydrolight RT model (Mobley 1994) with our extensions for UV ocean optical properties into the 290-400-nm wavelength range (Vasilkov et al. 2005). An essential component of the in-water RT model is a model of ocean water IOPs in the UV spectral region. The UV-IOP model used here is an extension of the Case I water model (Morel 1988) to the UV spectral region 290-400 nm (Vasilkov et al. 2005). A key element of the model is a parameterization of the chlorophyll-specific absorption coefficient as a function of chlorophyll concentration. This parameterization of particulate-matter absorption in the UV is based on in situ data collected in the framework of the California Cooperative Oceanic Fisheries Investigations (CalCOFI) (Kahru and Mitchell 1998). The particulate-matter absorption is expressed through a chlorophyll-a concentration and a chlorophyllspecific absorption coefficient. The latter in the UV is parameterized using a power law of chlorophyll concentration similar to that used in the visible part of spectrum (Vasilkov et al. 2005).

An important absorber in UV is the chromophoric (or colored) dissolved organic matter (CDOM), whose absorption increases exponentially with wavelength decreasing. The spectral CDOM absorption is parameterized in the conventional form (Morel 1988; Morel and Maritorena 2001):

$$
a_{\mathrm{CDOM}}=a_{\mathrm{CDOM}}\left(\lambda_{0}\right) \exp \left[S\left(\lambda-\lambda_{0}\right)\right],
$$

where $\lambda_{0}=440 \mathrm{~nm}$ is the reference wavelength, and $S$ is the spectral slope. A typical value of the spectral slope is $S=0.014 \mathrm{~nm}^{-1}$ (Morel and Maritorena 2001). However, the spectral slope exhibits higher values in the short-wavelength domain (Morel et al. 2007), which is why we assume $S=0.017 \mathrm{~nm}^{-1}$ (Kopelevich et al. 1989).

Another important feature of the IOP model is quantifying the pure water absorption in UV. At present there are no consensus values for the pure-water absorption coefficient in the UV. For instance, Morel et al. (2007) state that, "Indeed, laboratory measurements of pure water absorption, particularly in the violet and ultraviolet part of the spectrum are scarce and contradictory." A detailed discussion on pure water absorption can be found in the above referenced paper and in Vasilkov et al. (2002). In this study we use interpolation between data given in Pope and Fry (1997) and Quickenden and Irvin (1980) as recommended by Fry (2000).

To reduce a number of input parameters, the Case I water model (Morel 1988; Morel and Maritorena 2001) is assumed. According to this model, all ocean water constituents are of biogenic origin. That is why the IOPs of ocean water are assumed to be fully correlated and can be parameterized through chlorophyll concentration. The Case I ocean water model works well for open ocean waters where the influence of terragenic matter 
is negligible. The particulate-matter absorption coefficient is parameterized as follows: $a_{p}=A(\lambda) \mathrm{Ch}^{1-B(\lambda)}$, where the coefficients $A(\lambda)$ and $B(\lambda)$ are tabulated in Vasilkov et al. (2005). The CDOM absorption coefficient at $440 \mathrm{~nm}$ is parameterized using Eq. (18) of Morel and Maritorena (2001): $a_{\mathrm{CDOM}}(440)=$ $0.2\left[a_{w}(440)+0.06 \mathrm{Chl}^{0.65}\right]$, where $a_{w}=0.00635 \mathrm{~m}^{-1}$ is the pure seawater absorption coefficient (Morel et al. 2007).

The spectral dependence of the particulate matter scattering coefficient is approximated by a power law $b_{p}(\lambda)=b_{0}\left(\lambda / \lambda_{0}\right)^{-n}$, where $\lambda_{0}=550 \mathrm{~nm}$ is the reference wavelength, the power-law exponent $n=1$ (Morel 1988). A value of the particulate matter scattering coefficient at the reference wavelength is parameterized through chlorophyll concentration $b_{0}=0.416 \mathrm{Chl}^{0.766}$ (Morel and Maritorena 2001).

Thus, all the input parameters are functions of only one physical input quantity-the chlorophyll concentration. More details about the IOP model are given in Vasilkov et al. (2005). Additionally, we need to specify a phase-scattering function. An intercomparison of different phase scattering functions was carried out in Mobley et al. (2002) and Vasilkov et al. (2005). The Henyey-Greenstein phase function seems not to reproduce actual phase functions (Mobley et al. 2002). Data of this paper show that the physically based Fournier-Forand (FF) phase function (Fournier and Forand 1994) is better in predicting remote sensing reflectances and upwelling radiances in the visible than the average Petzold phase function at least for the near-surface layer of the ocean. Comparisons of the average Petzold and FF phase functions in the UV were carried out in Vasilkov et al. (2005). The comparisons of simulated ocean reflectance with in situ measured reflectance show that the FF phase function (Fournier and Forand 1994) provides better agreement of the data as compared with other phase functions. The FF phase function with a backscatter fraction 0.003 was used in the computations (Vasilkov et al. 2005).

The RT computations were conducted for vertically homogeneous waters. Lookup tables for in-water downward and upward irradiances were generated for chlorophyll concentrations that varied from 0.01 to $5 \mathrm{mg} \mathrm{m}^{-3}$ and for solar zenith angles (SZAs) ranging from $0^{\circ}$ to $80^{\circ}$.

\section{e. Verification of the model}

The accuracy of the in-water radiation field is mostly limited by errors in the IOP model. We verified the ocean reflectance model by comparisons of the calculated and measured diffuse reflectances. In situ data used in the comparisons are from measurements

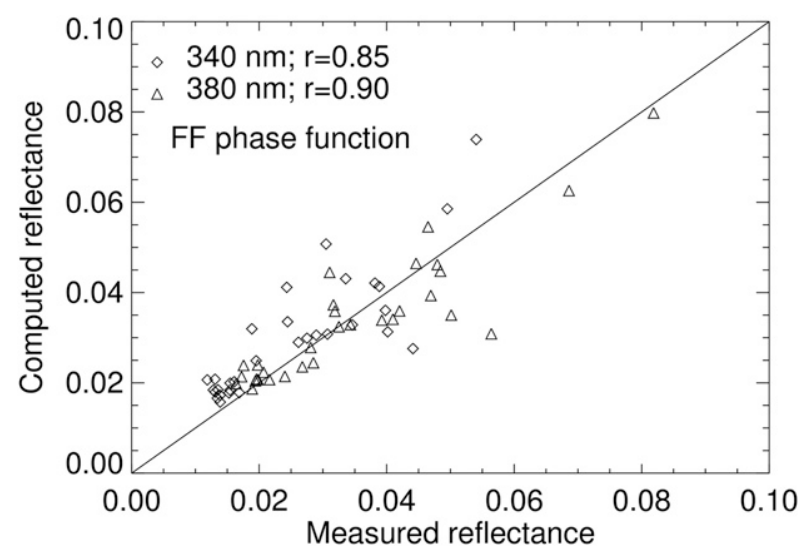

FIG. 1. Comparison of the computed in-water reflectance with the measured reflectance. The data are averaged over a 4-m upper layer.

taken during the Aerosol Characterization Experiment (ACE)-Asia experiment in the Pacific Ocean supported by the NASA SIMBIOS project (https://seabass.gsfc.nasa.gov/ experiment/ACE-ASIA). The measurements cover the time period from 16 March to 20 April 2001, while the spatial coverage of the data is from $25^{\circ}$ to $39^{\circ} \mathrm{N}$ and from $177^{\circ} \mathrm{W}$ to $178^{\circ} \mathrm{E}$. The underwater measurements were performed with the Biospherical Instruments PRR800 high-resolution, underwater profiling reflectance radiometer. The dataset includes profile measurements of downward irradiance $E_{d}$, upward irradiance $E_{u}$ at 17 wavelengths ranging from 313 to $710 \mathrm{~nm}$. The diffuse reflectance is determined as $R=E_{u} / E_{d}$. To reduce the noise, the measured quantities were averaged over a few meter layer. Measurements of surface chlorophyll concentration were also available for the same cruise.

Figure 1 compares the calculated reflectance with the measured reflectance at two wavelengths. The agreement between the data is good: the correlation coefficient is equal to 0.85 at $340 \mathrm{~nm}$ and 0.90 at $380 \mathrm{~nm}$. Figure 2 compares the calculated reflectance with the measured reflectance as a function of chlorophyll concentration. Spikes seen on the curves are caused by variations of the SZA at the cruise stations. The reflectance at $340 \mathrm{~nm}$ is lower than that at $380 \mathrm{~nm}$ because of higher total absorption at shorter wavelengths. It should be noted that the model reflectance at $340 \mathrm{~nm}$ is biased high by about 0.01 on average.

Figure 3 compares TOA radiances measured by Aura/OMI with TOA radiances calculated using the VLIDORT radiative transfer code (Spurr 2006) and our model of ocean water IOPs in UV (Vasilkov et al. 2005). Radiative transfer simulations are carried out at $354 \mathrm{~nm}$ for the Rayleigh atmosphere. We account for both Fresnel reflection from the rough water surface and diffuse light backscattered by water bulk and transmitted 


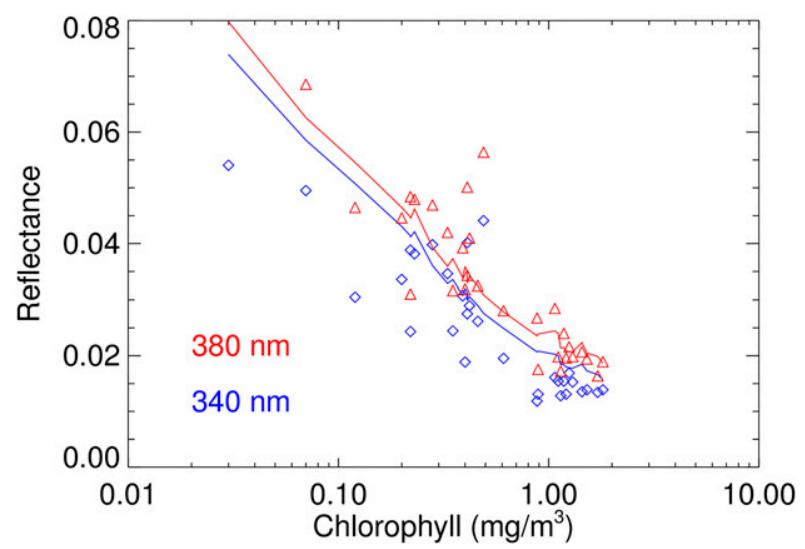

FIG. 2. Comparison of the computed reflectance (solid lines) with the measured reflectance for different chlorophyll concentrations.

through the water-atmosphere interface. A contribution from oceanic foam that can be significant for high wind speeds is neglected. Reflection from the water surface is described by the Cox-Munk slope distribution function. We use an isotropic form of the CoxMunk distribution in which the facet slope variance is independent of wind direction. All computations use a wind speed of $5 \mathrm{~m} \mathrm{~s}^{-1}$, which is close to the climatological mean. To compare with OMI observations, we selected OMI pixels for clear skies with minimum aerosol contamination. The comparison in Fig. 3 demonstrates a good agreement between the calculated and OMImeasured radiances for a wide range of OMI viewing and solar zenith angles. The TOA radiance differences are within a few percent.

\section{Results}

Figure 4 shows global maps of ocean reflectance derived from EPIC observations at 340 and $388 \mathrm{~nm}$. The maps are an average of the ocean reflectance data for January and July 2016. Regional gaps on the maps are mostly due to the lack of clear-sky observations for those regions. Figure 5 shows global maps of chlorophyll a concentrations from Aqua/MODIS for January and July 2016. The chlorophyll a concentration determines the IOPs of open ocean waters and to some extent of coastal waters. Comparison of the maps in Figs. 4 and 5 reveals strong inverse correlation and proves that the EPIC-derived ocean reflectance correctly reproduces the spatial distribution of oceanic chlorophyll on global and regional scales. The EPIC-derived ocean reflectance also correctly captures seasonal variability of oceanic chlorophyll concentration.

Figure 6 shows maps of the simulated ocean reflectance at 340 and $388 \mathrm{~nm}$. The simulations were carried out using chlorophyll concentrations for July 2016 derived from Aqua/MODIS and shown in Fig. 5. Visual comparison of the maps of EPIC-derived (Fig. 4) and simulated ocean reflectance (Fig. 6) shows a qualitative agreement of the spatial distributions of ocean reflectance on global and regional scales. There is also a qualitative agreement of the spectral dependence of ocean reflectance: both satellite-derived and simulated reflectances are systematically lower at shorter wavelength of $340 \mathrm{~nm}$.

However, there are some quantitative differences between the satellite-derived and simulated ocean
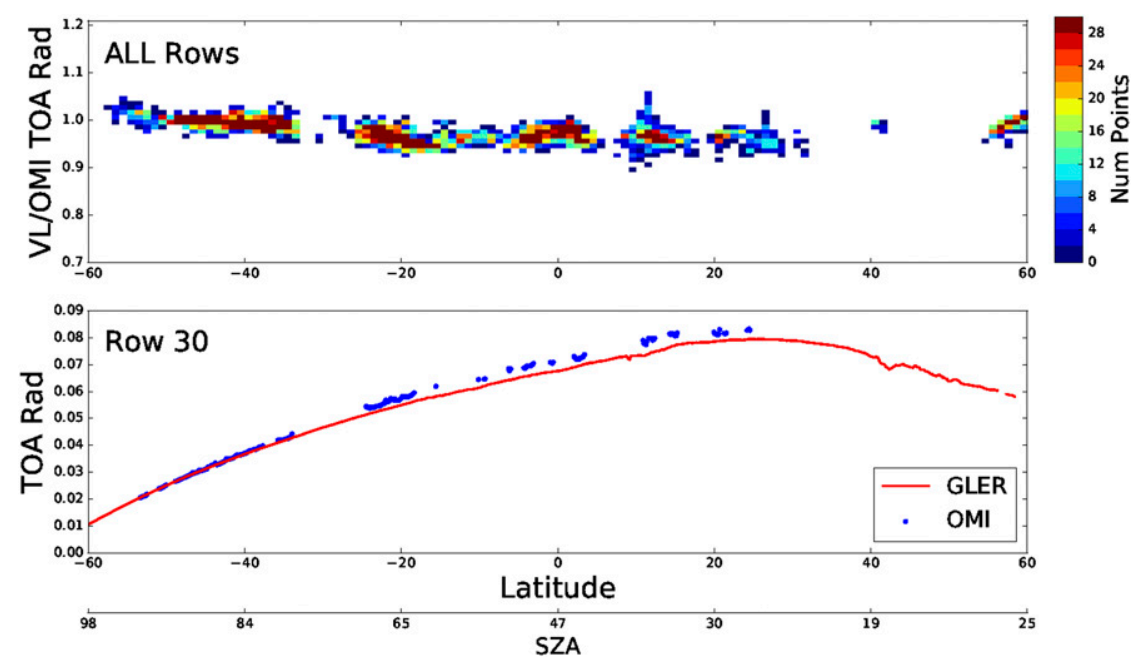

FIG. 3. Comparison of calculated TOA radiances with OMI measurements of orbit 10815 (27 Jul 2006). (top) Ratio of the computed TOA radiance to the measured radiance as a function of latitude; all OMI rows with different viewing zenith angles are shown. (bottom) TOA radiance computed for OMI nadir view (row 30; red line) and OMI observations (blue dots). 

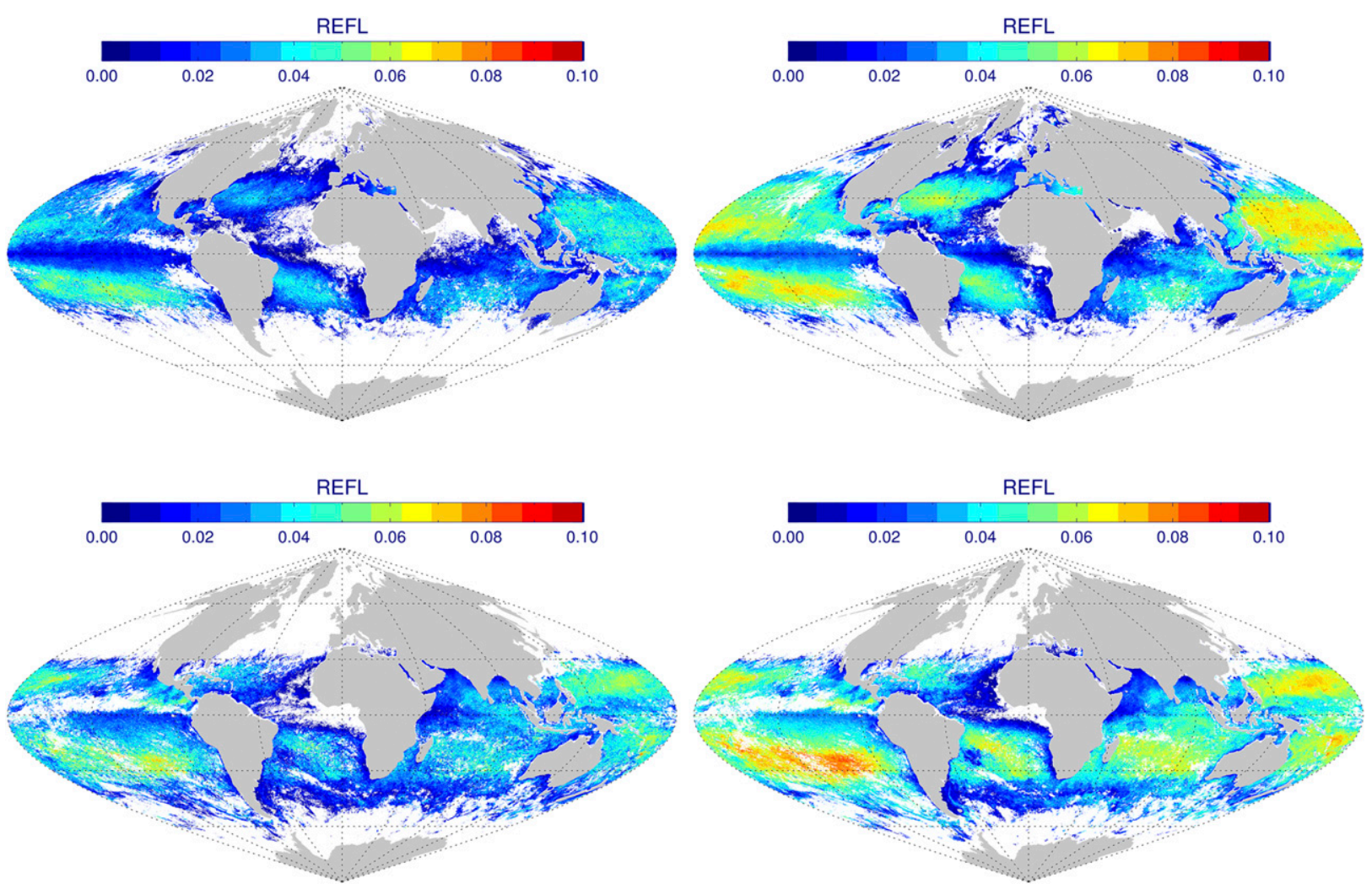

FIG. 4. EPIC-derived ocean reflectance at (left) 340 and (right) $388 \mathrm{~nm}$ for (top) July and (bottom) January 2016.

reflectances (Fig. 7). Those differences are clearly seen in the oligotrophic areas of the ocean with low chlorophyll concentrations. The EPIC-derived reflectance is noticeably higher than the simulated reflectance over those areas. Over mesotrophic and eutrophic areas of the ocean with chlorophyll concentration about $0.15 \mathrm{mg} \mathrm{m}^{-3}$ and larger, the EPIC-derived reflectance is generally lower than the simulated reflectance.

To analyze the reflectance differences in detail, we calculated histograms of the reflectance differences and plotted the mean differences and standard deviations as a function of chlorophyll concentration. Figure 8 shows histograms of the ocean reflectance differences (model minus EPIC) at 340 and $388 \mathrm{~nm}$ for January and July 2016. The most striking feature of the histograms is the seasonal dependence of the reflectance differences. The 340-nm histogram for January has a maximum value at the zero difference while the histogram for July has a maximum value at the reflectance difference of about 0.008 . The reverse takes
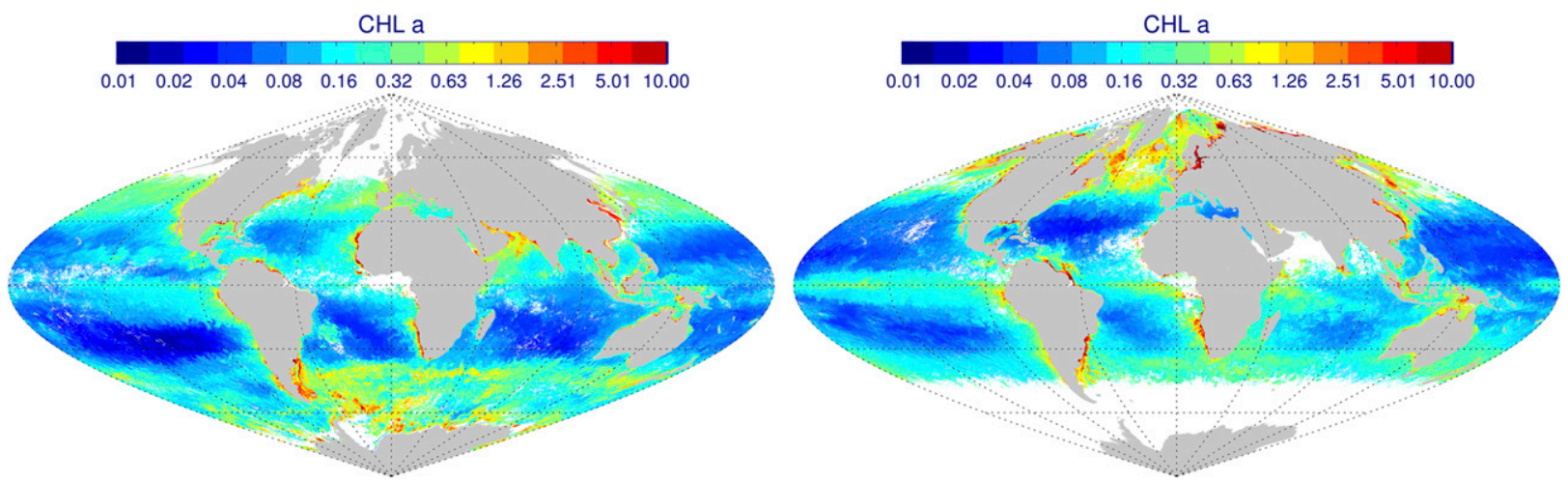

FIG. 5. Aqua/MODIS-derived chlorophyll concentration for (left) January and (right) July 2016. 

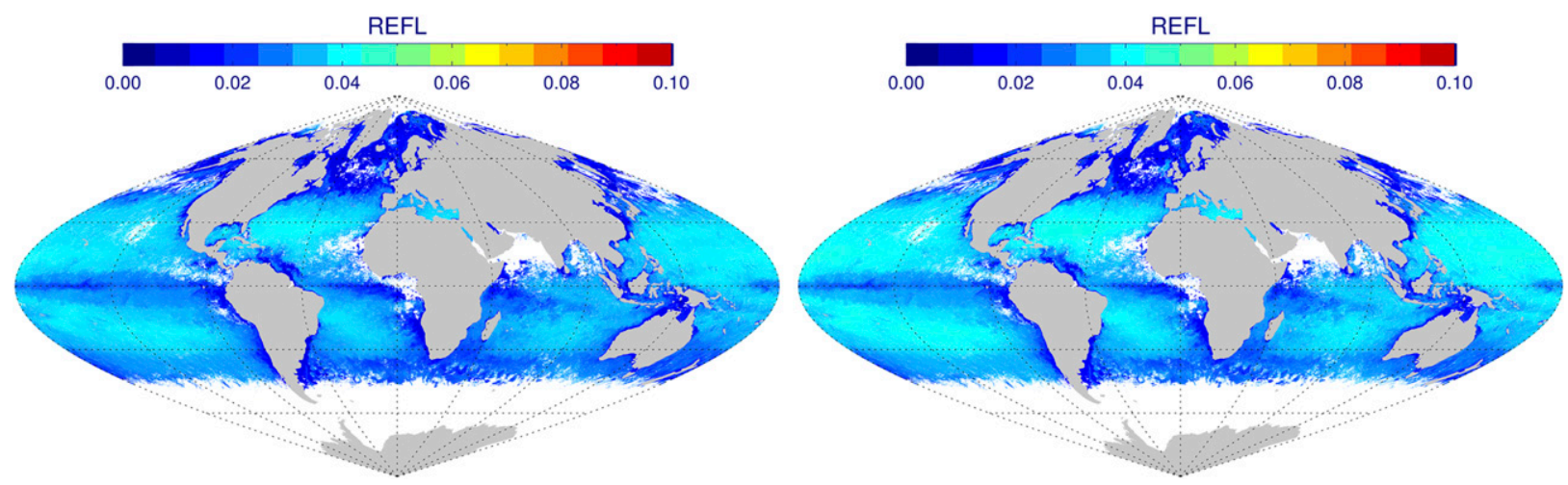

FIG. 6. Model ocean reflectance at (left) 340 and (right) $388 \mathrm{~nm}$.

place for the 388-nm histogram: it is biased low for January and has a maximum value at the zero difference for July. For the 388-nm histograms most reflectance difference data are in the negative regions. The 340-nm histograms show that the model data are biased high. The 388-nm histograms are not symmetric: the histogram for January is slightly skewed to the right while the histogram for July is skewed to the left.

Figures 9 and 10 show the mean difference (model minus EPIC) and standard deviation as a function of chlorophyll. The data in Figs. 9 and 10 confirm the qualitative conclusion that the model somewhat underestimates ocean reflectance for chlorophyll concentrations lower than about $0.1 \mathrm{mg} \mathrm{m}^{-3}$. For those chlorophyll concentrations, the model reflectance at $388 \mathrm{~nm}$ is biased low by about $0.01-0.03$. This bias is more pronounced for January than for July. The bias of the model reflectance at $340 \mathrm{~nm}$ is smaller; it is within 0.01 . For chlorophyll concentrations higher than $0.1 \mathrm{mg} \mathrm{m}^{-3}$, the model data well agree with EPIC retrievals (within 0.01).

The OMI-derived climatological LERs (Fig. 11) are significantly higher than the EPIC-derived ocean reflectance. Histograms of the differences between LER and EPIC-derived reflectance show that the most probable difference is about 0.04 . Such a large difference (LER minus EPIC) is expected because the climatological LERs include a contribution from inevitable aerosol contamination. Additionally, OMI reflectance combines water-leaving signal with Fresnel reflectance from wind-ruffled ocean surface On the contrary, the MAIAC processing removes the Fresnel and whitecap reflection as a function of NCEP wind speed providing the diffuse ocean reflectance only.

\section{Discussion}

There is a vast area in the mid-Atlantic where the model reflectance is significantly higher than the EPICderived reflectance. This area is usually associated with the transatlantic dust aerosol transport from the Sahara to North America (Kaufman et al. 2005). Absorption of dust aerosol is spectrally dependent and strongly increases in UV (Sokolik and Toon 1999). Current MAIAC dust aerosol model over ocean has a fixed imaginary refractive index $(0.002)$, which provides a
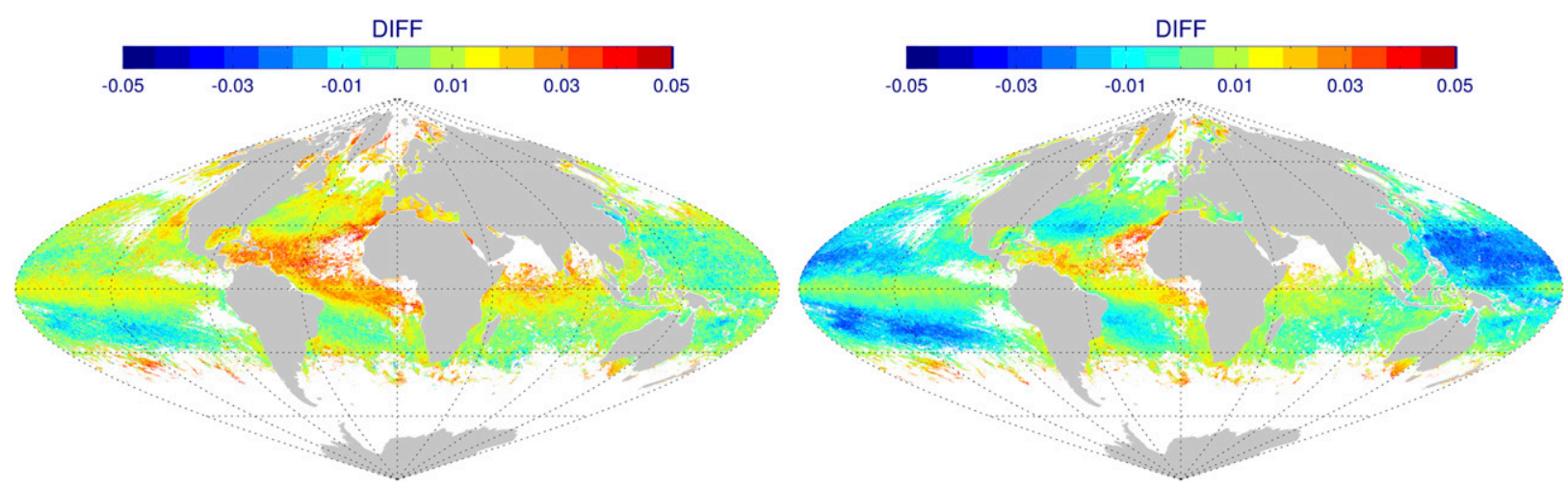

FIG. 7. Maps of the ocean reflectance differences (model minus EPIC) at (left) 340 and (right) 388 nm for July 2016. 

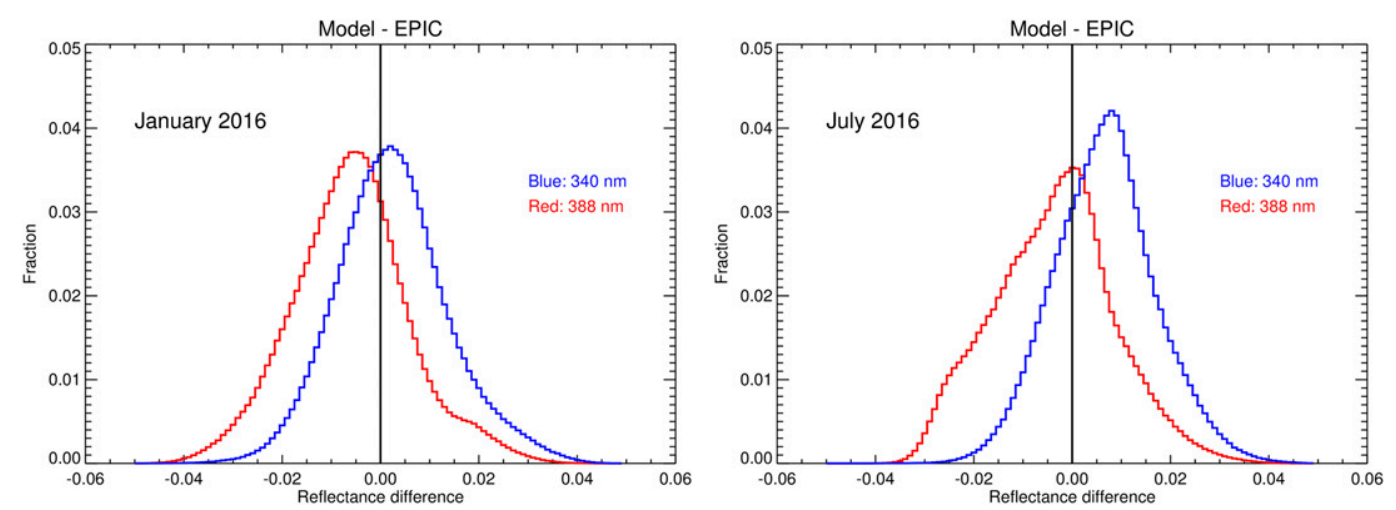

FIG. 8. Histograms of the ocean reflectance differences (model minus EPIC) for (left) January and (right) July 2016.

good validation of AOD against AERONET at $550 \mathrm{~nm}$; however, it clearly underestimates aerosol absorption and, therefore, the ocean reflectance at shorter wavelengths, in particular in the UV.

To quantify the sensitivity of ocean reflectance to aerosol absorption, we conducted test retrievals in the equatorial Atlantics in summer of 2016, peak of the dust season, using a realistic spectral dependence of the imaginary refractive index of dust. While the laboratory and field measurements of the Saharan dust show a wide range of absorption depending mostly on hematite content (e.g., Wagner et al. 2012), we relied on the summary of Russell et al. (2010) providing the absorption Ångström exponent (AAE) 2.3 for Saharan dust. Similarly, to standard Ångström exponent, the AAE explains spectral dependence of the aerosol absorption optical thickness. Our retrievals using AAE $=2.5$ showed an increase in the individual pixel-level waterleaving reflectance of up to 0.04 , with increase in the monthly average values of $0.01-0.025$. This test shows that the use of more realistic dust model will help reconcile EPIC reflectance with the model and reduce the observed differences.

The ocean reflectance for low productive waters with low chlorophyll concentrations depends mostly on absorbing and scattering properties of pure ocean water. While the pure ocean water scattering coefficient is well known in UV, the pure ocean absorption coefficient is still not reliably established (Vasilkov et al. 2002; Morel et al. 2007; Lee et al. 2015; Mason et al.2016). Uncertainties of the ocean reflectance can be estimated assuming that the reflectance is proportional to the ratio of the backscattering coefficient to the absorption coefficient $\rho_{w} \sim b_{b} / a$ (Morel and Gentili 1996). Then the ocean reflectance uncertainty due to the absorption coefficient uncertainty is $\Delta \rho_{w}=\rho_{w} \Delta a / a$. The underestimation of the modeled ocean reflectance for low productive waters could indicate that values of the pure water absorption in UV could be overestimated. However, the systematic underestimation of the modeled reflectance for both seasons of January and July takes place for the reflectance at $388 \mathrm{~nm}$ only. At $340 \mathrm{~nm}$, the underestimation of the modeled reflectance occurs in January only. This seasonal variability of the bias between the EPIC-derived and modeled reflectances for low productive waters is not understood. However, this may be related to the finding by Lee and $\mathrm{Hu}$ (2006). They studied the global distribution of Case 1 water and reported that "seasonally, there is no substantial change in the total percentage of Case 1 waters from spring to autumn, but the percentage drops significantly in winter."

We compared the values of the pure water absorption coefficient used in the present paper with those reported in the recent papers. Figure 12 shows our data [interpolation between data given in Pope and Fry (1997) and Quickenden and Irvin (1980)] along with more
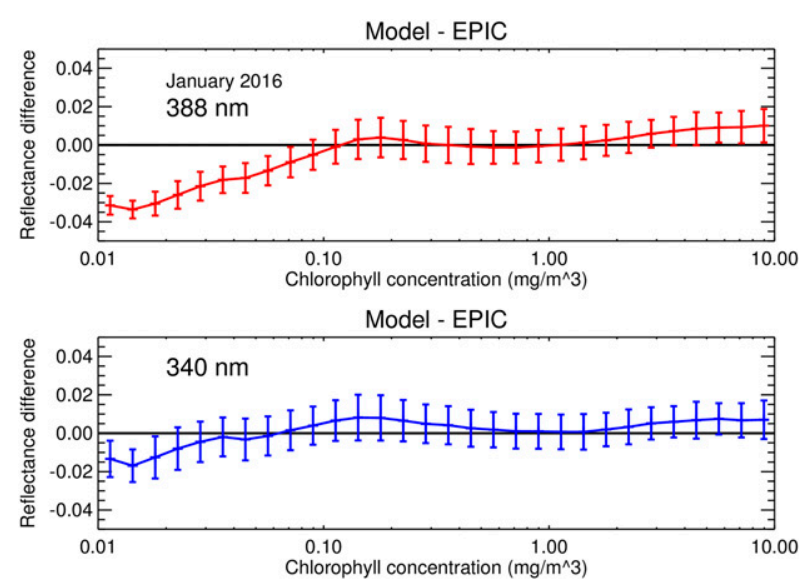

FIG. 9. Mean and standard deviation of ocean reflectance differences (model minus EPIC) as a function of chlorophyll concentration. Data are at (top) 388 and (bottom) $340 \mathrm{~nm}$ for January 2016. 


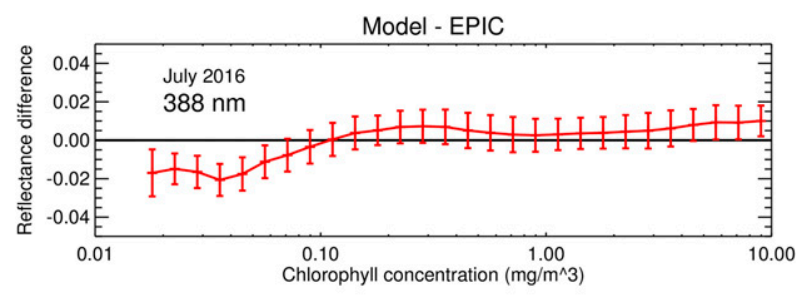

Model - EPIC

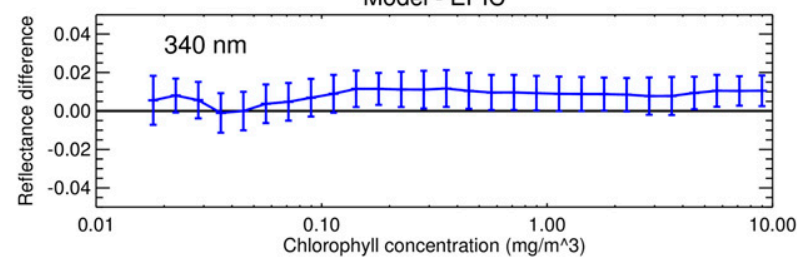

FIG. 10. As in Fig. 9, but for July 2016.

recent data from Morel et al. (2007) and Lee et al. (2015). We do not show the measured data by Mason et al. (2016) because they are substantially lower than those shown in Fig. 12. We also do not show the old data by Smith and Baker (1981) because they are substantially higher than those shown in Fig. 12. Our absorption coefficients are in the good agreement with the measurements by Pope and Fry (1997) and Sogandares and Fry (1997). However, they are somewhat higher than the data recommended by Morel et al. (2007) and substantially higher than the water absorption data inverted from remote sensing reflectance by Lee et al. (2015). If we assume that the total absorption is dominated by the pure water absorption then we can estimate the ocean reflectance uncertainty due to the pure water uncertainty. Using the data in Fig. 12 we evaluate the relative error in the ocean reflectance, $\Delta \rho_{w} / \rho_{w}$ as $31 \%$ at $340 \mathrm{~nm}$ and $40 \%$ at $388 \mathrm{~nm}$ for the data by Morel et al. (2007) and $42 \%$ and $57 \%$, respectively, for the data by Lee et al. (2015). These estimates are actually an upper limit because we neglect phytoplankton pigment and CDOM contributions to the total absorption. The estimates show that the modeled reflectance at $388 \mathrm{~nm}$ can be brought to the agreement with the EPIC-derived reflectance for low chlorophyll concentrations if we use the data by Lee et al. (2015). However, those data were not derived from direct measurements; they were retrieved from comparisons of the simulated and measured remote sensing by adjusting the pure water absorption coefficient to get a reasonable agreement between the simulated and measured data. The Case 1 ocean water model was used for the simulations but with the parameterizations of absorbing and scattering properties of water, which are different from our parameterizations. Moreover, inverted values of the pure water absorption coefficient in Vis appear to be noticeably lower than the consensus values derived from measurements and reported in Pope and Fry (1997), Sogandares and Fry (1997), and Morel et al. (2007). The lack of consensus indicates that further studies of the pure water absorption in UV are needed before they can be used for quantitative analysis.

Here we implemented the Case 1 water model that is assumed to be representative of the global oceans with dependence only on chlorophyll concentration. The model contains a few parameterizations of IOPs through chlorophyll concentration. The parameterizations may not be representative on a global scale. For instance, Szeto et al. (2011) showed that the world oceans are optically different and that optical parameters such as chlorophyll absorption change even for Case 1 open ocean waters. Work by Lee and $\mathrm{Hu}$ (2006) similarly showed that even for open ocean water, large deviations exist from the presumed Case 1 water model due to uncertainty in the optical properties used to parameterize the models. They determined that only approximately $60 \%$ of the global surface water belongs to the Case 1 model. Given the uncertainties related to the
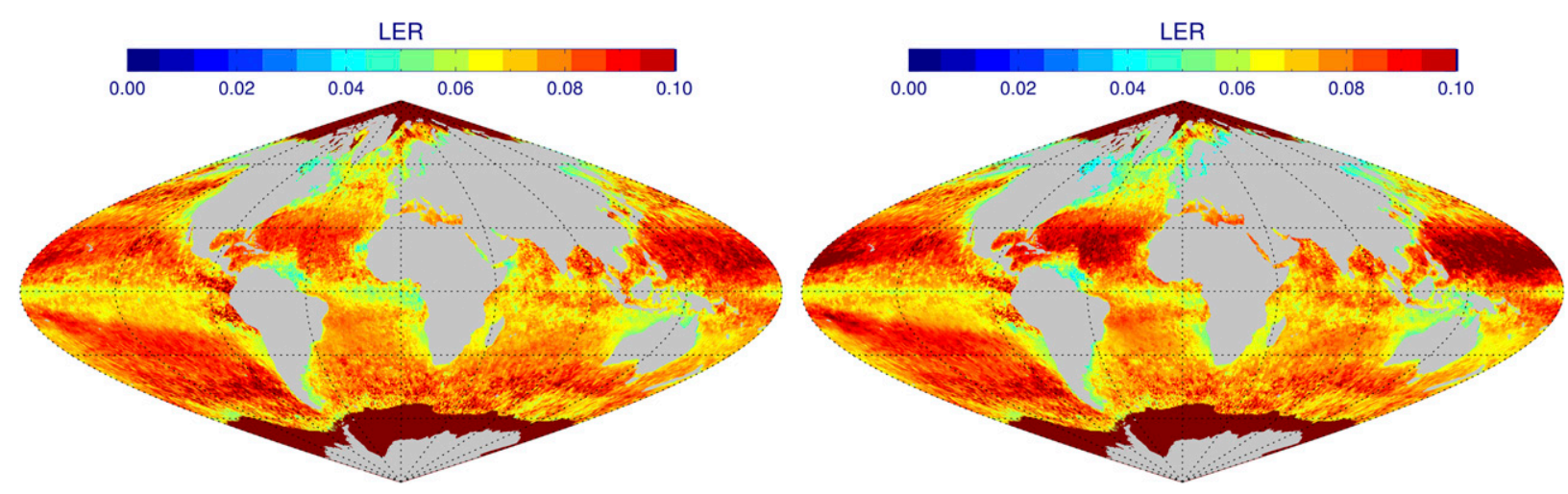

FIG. 11. OMI-derived minimum LER climatology for (left) 340 and (right) $388 \mathrm{~nm}$. Data are July. 


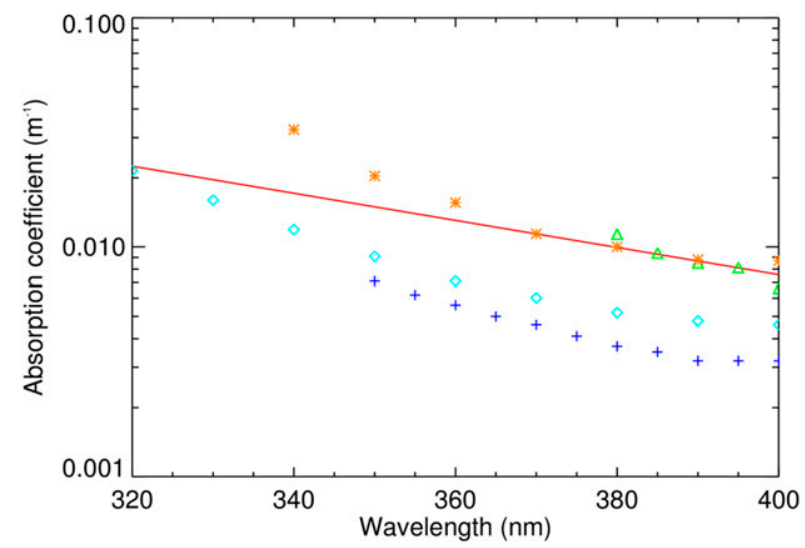

FIG. 12. Comparison of our pure water absorption coefficient (solid line) with literature data: measurements by Sogandares and Fry (1997; yellow stars), measurements by Pope and Fry (1997; green triangles), data recommended by Morel et al. (2007; light blue squares), and data inverted from remote sensing reflectance by Lee et al. (2015; blue plus signs).

Case 1 water model, the achieved agreement between the modeled and EPIC-derived ocean reflectances is reasonably good.

\section{Conclusions}

This work gives the first analysis of the recently released new NASA EPIC product, namely, MAIAC diffuse ocean reflectance reported as part of the surface reflectance suite. The EPIC-derived ocean reflectance is found to correctly capture both the spatial and seasonal variability of oceanic chlorophyll, which mainly determines the inherent optical properties of the open ocean waters.

The EPIC reflectance agrees well (within 0.01) with the model reflectance except for oligotrophic oceanic areas with chlorophyll concentrations lower than about $0.1 \mathrm{mg} \mathrm{m}^{-3}$. For those areas, the model reflectance is biased low by about 0.01 at $340 \mathrm{~nm}$ and up to 0.03 at $388 \mathrm{~nm}$. This work also revealed a deficiency of current MAIAC dust aerosol model over ocean, which does not account for the increase in dust absorption in the blue-UV spectrum. This results in underestimation of the ocean diffuse reflectance in central Atlantics during the Saharan dust season peaking in summer. Similar effect may be observed in the north-equatorial Asian Pacific in spring due to Asian dust outflows. This omission will be corrected in the v2 EPIC reprocessing expected in late 2019.

The EPIC-derived diffuse ocean reflectance is significantly lower than the OMI-derived climatological LER representing total reflectance including Fresnel and whitecaps contribution from the wind-ruffled water surface. The globally averaged difference (LER minus EPIC) is about 0.04. Besides glint and foam, an additional small component of this difference may be due to the residual uncompensated aerosol backscattering in the climatological OMI LERs.

The algorithms and approaches described in the paper are relevant to the future Plankton, Aerosol, Cloud, ocean Ecosystem (PACE) mission. PACE is currently in the design phase of mission development. It is scheduled to launch in 2022. Global PACE observations will provide data to monitor oceanic and atmospheric variables important for Earth system and climate studies. The PACE Ocean Color Instrument (OCI) is designed as a wide-swath imaging radiometer with a $1-\mathrm{km}$ ground nadir resolution, a 5-nm spectral resolution between 350 and $890 \mathrm{~nm}$, and several shortwave infrared bands. As compared with SeaWiFS, MODIS, and VIIRS, the OCI will additionally measure TOA radiances in the UV to help identify phytoplankton composition and harmful algal blooms. As it stated in the recent PACE report (Cetinic et al. 2018), "PACE's high spectral resolution in the UV-A to green wavelength region and in the red-NIR will allow unparalleled evaluation of ecosystem properties in optically complex waters and in regions of increasing eutrophication."

Acknowledgments. We thank W. Qin and Z. Fasnacht of SSAI for providing data for Fig. 3. The lead author acknowledges support through the NASA OMI Core Funding and from the PACE Science Team via Award NNX15AC98G to B. G. Mitchell. The work of A. Lyapustin and D. Huang was supported through funding to the DSCOVR Science Team (Dr. R. Eckman).

\section{REFERENCES}

Arrigo, K. R., 1994: The impact of ozone depletion on phytoplankton growth in the Southern Ocean: Large-scale spatial and temporal variability. Mar. Ecol. Prog. Ser., 114, 1-12, https://doi.org/10.3354/meps114001.

Cetinic I., C. R. McClain, and P. J. Werdell, Eds., 2018: PreAerosol, Clouds, and ocean Ecosystem (PACE) Mission Science Definition Team report. PACE Tech. Rep. NASA/TM2018-219027, Vol. 2, 316 pp.

Fichot, C. G., S. Sathyendranath, and W. L. Miller, 2008: SeaUV and SeaUVC: Algorithms for the retrieval of UV/visible diffuse attenuation coefficients from ocean color. Remote Sens. Environ., 112, 1584-1602, https://doi.org/10.1016/j.rse.2007.08.009.

Fournier, G., and J. L. Forand, 1994: Analytic phase functions for ocean water. Proc. SPIE, 2258, 194-201, https://doi.org/ 10.1117/12.190063.

Fry, E. S., 2000: Visible and near ultraviolet absorption spectrum of liquid water. Appl. Opt., 39, 2743-2744, https://doi.org/10.1364/ AO.39.002743.

Geogdzhayev, I. V., and A. Marshak, 2018: Calibration of the DSCOVR EPIC visible and NIR channels using MODIS 
and EPIC lunar observations. Atmos. Meas. Tech., 11, 359368, https://doi.org/10.5194/amt-11-359-2018.

Gordon, H. R., 1997: Atmospheric correction of ocean color imagery in the Earth Observing System era. J. Geophys. Res., 102, 17 081-17 106, https://doi.org/10.1029/96JD02443.

_ aerosol optical thickness over the oceans with SeaWiFS: A preliminary algorithm. Appl. Opt., 33, 443-452, https://doi.org/ 10.1364/AO.33.000443.

Hader, D.-P., H. D. Kumar, R. C. Smith, and R. C. Worrest, 2007: Effects of solar UV radiation on aquatic ecosystems and interactions with climate change. Photochem. Photobiol. Sci., 6, 267-285, https://doi.org/10.1039/B700020K.

Herman, J. R., and E. Celarier, 1997: Earth surface reflectivity climatology at 340 to $380 \mathrm{~nm}$ from TOMS data. J. Geophys. Res., 102, 28 003-28 011, https://doi.org/10.1029/97JD02074.

—-, L. Huang, R. D. McPeters, J. Ziemke, A. Cede, and K. Blank, 2018: Synoptic ozone, cloud reflectivity, and erythemal irradiance from sunrise to sunset for the whole Earth as viewed by DSCOVR spacecraft from the Earth-sun Lagrange-1 orbit. Atmos. Meas. Tech., 11, 177-194, https:// doi.org/10.5194/amt-11-177-2018.

Holben, B. N., and Coauthors, 2001: An emerging ground-based aerosol climatology: Aerosol optical depth from AERONET. J. Geophys. Res., 106, 12 067-12 097, https://doi.org/10.1029/ 2001JD900014.

Kahru, M., and B. G. Mitchell, 1998: Spectral reflectance and absorption of a massive red tide off Southern California. J. Geophys. Res., 103, 21 601-21 609, https://doi.org/10.1029/ 98JC01945.

Kaufman, Y. J., I. Koren, L. A. Remer, D. Tanré, P. Ginoux, and S. Fan, 2005: Dust transport and deposition observed from the Terra-Moderate Resolution Imaging Spectroradiometer (MODIS) spacecraft over the Atlantic Ocean. J. Geophys. Res., 110, D10S12, https://doi.org/10.1029/2003JD004436.

Kleipool, Q. L., M. R. Dobber, J. F. de Haan, and P. F. Levelt, 2008: Earth surface reflectance climatology from 3 years of OMI data. J. Geophys. Res., 113, D18308, https://doi.org/10.1029/ 2008JD010290.

Kopelevich, O. V., S. V. Lutsarev, and V. V. Rodionov, 1989: Light spectral absorption by yellow substance of ocean water. Oceanology, 29, 409-414.

Korkin, S., A. Lyapustin, and V. Rozanov, 2013: APC: A new code for atmospheric polarization computations. J. Quant. Spectrosc. Radiat. Transfer, 127, 1-11, https://doi.org/10.1016/ j.jqsrt.2013.06.019.

Lee, Z., and C. Hu, 2006: Global distribution of Case-1 waters: An analysis from SeaWiFS measurements. Remote Sens. Environ., 101, 270-276, https://doi.org/10.1016/j.rse.2005.11.008.

S. Shang, K. Du, M. Lewis, R. Arnone, and R. Brewin, 2013: Penetration of UV-visible solar radiation in the global oceans: Insights from ocean color remote sensing, J. Geophys. Res. Oceans, 118, 4241-4255, https://doi.org/ 10.1002/jgrc. 20308.

— J. Wei, K. Voss, M. Lewis, A. Bricaud, and Y. Huot, 2015: Hyperspectral absorption coefficient of "pure" seawater in the range of $350-550 \mathrm{~nm}$ inverted from remote sensing reflectance. Appl. Opt., 54, 546-558, https://doi.org/10.1364/ AO.54.000546.

Levy, R. C., S. Mattoo, L. A. Munchak, L. A. Remer, A. M. Sayer, F. Patadia, and N. C. Hsu, 2013: The Collection 6 MODIS aerosol products over land and ocean. Atmos. Meas. Tech., 6 , 2989-3034, https://doi.org/10.5194/amt-6-2989-2013.
Lyapustin, A., 2005: Radiative transfer code SHARM for atmospheric and terrestrial applications. Appl. Opt., 44, 7764-7772, https://doi.org/10.1364/AO.44.007764.

— , Y. Wang, I. Laszlo, T. Hilker, F. Hall, P. Sellers, J. Tucker, and S. Korkin, 2012: Multi-angle implementation of atmospheric correction for MODIS (MAIAC). 3: Atmospheric correction. Remote Sens. Environ., 127, 385-393, https:// doi.org/10.1016/j.rse.2012.09.002.

$\longrightarrow,-$ S. Korkin, and D. Huang, 2018: MODIS Collection 6 MAIAC algorithm. Atmos. Meas. Tech., 11, 5741-5765, https://doi.org/10.5194/amt-11-5741-2018.

Marshak, A., and Coauthors, 2018: Earth observations from DSCOVR/EPIC instrument. Bull. Amer. Meteor. Soc., 99, 1829-1850, https://doi.org/10.1175/BAMS-D-17-0223.1

Mason, J. D., M. T. Cone, and E. S. Fry, 2016: Ultraviolet (250$550 \mathrm{~nm}$ ) absorption spectrum of pure water. Appl. Opt., 55, 7163-7172, https://doi.org/10.1364/AO.55.007163.

Mobley, C. D., 1994: Light and Water: Radiative Transfer in Natural Waters. Academic Press, 592 pp.

— L. K. Sundman, and E. Boss, 2002: Phase function effects on oceanic light fields. Appl. Opt., 41, 1035-1050, https://doi.org/ 10.1364/AO.41.001035.

_ J. Werdel, B. Franz, Z. Ahmad, and S. Bailey, 2016: Atmospheric correction for satellite ocean color radiometry. NASA Tech. Memo. NASA/TM-2016-217551, 85 pp., https://ntrs.nasa.gov/ search.jsp?R=20160011399.

Moran, M. A., and R. G. Zepp, 1997: Role of photoreactions in the formation of biologically labile compounds from dissolved organic matter. Limnol. Oceanogr., 42, 1307-1316, https:// doi.org/10.4319/lo.1997.42.6.1307.

Morel, A., 1988: Optical modeling of the upper ocean in relation to its biogeneous matter content (Case I waters). J. Geophys. Res., 93, 10 749-10 768, https://doi.org/10.1029/JC093iC09p10749.

_ III: Implication of bidirectionality for the remote-sensing problem. Appl. Opt., 35, 4850-4862, https://doi.org/10.1364/ AO.35.004850.

— waters: A reappraisal. J. Geophys. Res., 106, 7163-7180, https://doi.org/10.1029/2000JC000319.

_ B. Gentili, H. Claustre, M. Babin, A. Bricaud, J. Ras, and F. Tieche, 2007: Optical properties of the "clearest" natural waters. Limnol. Oceanogr., 52, 217-229, https://doi.org/ 10.4319/1o.2007.52.1.0217.

Neale, P. J., R. F. Davis, and J. J. Cullen, 1998: Interactive effects of ozone depletion and vertical mixing on photosynthesis of Antarctic phytoplankton. Nature, 392, 585-589, https:// doi.org/10.1038/33374.

Pope, R. M., and E. S. Fry, 1997: Absorption spectrum (380-700 nm) of pure water. II. Integrating cavity measurements. Appl. Opt., 36, 8710-8723, https://doi.org/10.1364/AO.36.008710.

Quickenden, T. I., and J. A. Irvin, 1980: The ultraviolet absorption spectrum of liquid water. J. Chem. Phys., 72, 4416-4428, https://doi.org/10.1063/1.439733.

Russell, P. B., and Coauthors, 2010: Absorption Angstrom exponent in AERONET and related data as an indicator of aerosol composition. Atmos. Chem. Phys., 10, 1155-1169, https:// doi.org/10.5194/acp-10-1155-2010.

Sayer, A. M., N. C. Hsu, C. Bettenhausen, Z. Ahmad, B. N. Holben, A. Smirnov, G. E. Thomas, and J. Zhang, 2012: SeaWiFS Ocean Aerosol Retrieval (SOAR): Algorithm, validation, and comparison with other data sets. J. Geophys. Res., 117, D03206, https://doi.org/10.1029/2011JD016599. 
,-- J. Lee, C. Bettenhausen, W. V. Kim, and A. Smirnov, 2018a: Satellite Ocean Aerosol Retrieval (SOAR) algorithm extension to S-NPP VIIRS as part of the "Deep Blue" aerosol project. J. Geophys. Res. Atmos., 123, 380-400, https://doi.org/ 10.1002/2017JD027412.

—_ and Coauthors, 2018b: Validation of SOAR VIIRS overwater aerosol retrievals and context within the global satellite aerosol data record. J. Geophys. Res. Atmos., 123, 13 496-13 526, https://doi.org/10.1029/2018JD029465.

Schenkeveld, V. M. E., G. Jaross, S. Marchenko, D. Haffner, Q. L. Kleipool, N. C. Rozemeijer, J. P. Veefkind, and P. F. Levelt, 2017: In-flight performance of the Ozone Monitoring Instrument. Atmos. Meas. Tech., 10, 1957-1986, https:// doi.org/10.5194/amt-10-1957-2017.

Smith, R. C., and K. C. Baker, 1981: Optical properties of the clearest natural waters. Appl. Opt., 20, 177-186, https:// doi.org/10.1364/AO.20.000177.

_ , and J. J. Cullen, 1995: Effects of UV radiation on phytoplankton. Rev. Geophys., 33, 1211-1223, https://doi.org/10.1029/ 95RG00801.

Smyth, T. J., 2011: Penetration of UV irradiance into the global ocean. J. Geophys. Res., 116, C11020, https://doi.org/10.1029/ 2011JC007183.

Sogandares, F. M., and E. S. Fry, 1997: Absorption spectrum $\sim 340-700 \mathrm{~nm}$ of pure water. 1. Photothermal measurements. Appl. Opt., 36, 8699-8709, https://doi.org/10.1364/ AO.36.008699.

Sokolik, I. N., and O. B. Toon, 1999: Incorporation of mineralogical composition into models of the radiative properties of mineral aerosol from UV to IR wavelengths. J. Geophys. Res. 104, 9423-9444, https://doi.org/10.1029/1998JD200048.

Spurr, R. J. D., 2006: VLIDORT: A linearized pseudo-spherical vector discrete ordinate radiative transfer code for forward model and retrieval studies in multilayer multiple scattering media. J. Quant. Spectrosc. Radiat. Transfer, 102, 316-421, https://doi.org/10.1016/j.jqsrt.2006.05.005.

Szeto, M., P. J. Werdell, T. S. Moore, and J. W. Campbell, 2011: Are the world's oceans optically different? J. Geophys. Res., 116, C00H04, https://doi.org/10.1029/2011JC007230.
Torres, O., A. Tanskanen, B. Veihelmann, C. Ahn, R. Braak, P. K. Bhartia, P. Veefkind, and P. Levelt, 2007: Aerosols and surface UV products from Ozone Monitoring Instrument observations: An overview. J. Geophys. Res., 112, D24S47, https://doi.org/10.1029/2007JD008809

Vasilkov, A. P., and N. A. Krotkov, 1997: Modeling the effect of seawater optical properties on the ultraviolet radiant fluxes in the ocean. Izv. Atmos. Ocean. Phys., 33, 349-357.

,-- J. Herman, C. McClain, K. Arrigo, and W. Robinson, 2001: Global mapping of underwater UV irradiances and DNA-weighted exposures using TOMS and SeaWiFS data products. J. Geophys. Res., 106, 27 205-27219, https://doi.org/ 10.1029/2000JC000373.

_ J. Herman, N. A. Krotkov, M. Kahru, B. G. Mitchell, and C. Hsu, 2002: Problems in assessment of the ultraviolet penetration into natural waters from space-based measurements. Opt. Eng., 41, 3019-3027, https://doi.org/ 10.1117/1.1516822.

, - Z Z. Ahmad, M. Kahru, and B. G. Mitchell, 2005: Assessment of the ultraviolet radiation field in ocean waters from space-based measurements and full radiative-transfer calculations. Appl. Opt., 44, 2863-2869, https://doi.org/10.1364/ AO.44.002863.

Vincent, W. F., and J. J. Neale, 2000: Mechanism of UV damage in aquatic organisms. The Effects of $U V$ Radiation on Marine Ecosystems, S. J. de Mora, S. Demers, and M. Vernet, Eds., Cambridge University Press, 149-176.

Wagner, R., T. Ajtai, K. Kandler, K. Lieke, C. Linke, T. Muller, M. Schnaiter, and M. Vragel, 2012: Complex refractive indices of Saharan dust samples. Atmos. Chem. Phys., 12, 2491-2512, https://doi.org/10.5194/acp-12-2491-2012.

Wang, M., and H. Gordon, 1994: Radiance reflected from the ocean-atmosphere system: Synthesis from individual components of the aerosol size distribution. Appl. Opt., 33, 7088-7095, https://doi.org/10.1364/AO.33.007088.

Zepp, R. G., and M. O. Andreae, 1994: Factors affecting the photochemical production of carbonyl sulfide in seawater. Geophys. Res. Lett., 21, 2813-2816, https://doi.org/10.1029/ 94GL03083. 